\title{
Social class, smoking and the severity of respiratory symptoms in the general population
}

\author{
Paul M Trinder, Peter R Croft, Martyn Lewis
}

\begin{abstract}
Study objective-The prevalence of respiratory symptoms has been found in some studies to vary with social class. One explanation of this link may be the effect of exposure to cigarette smoke. To investigate this, the relation between social class, smoking and respiratory symptoms was explored in a population based survey. Design-A cross sectional survey using a validated questionnaire. Setting-Two general practices in Staffordshire, United Kingdom.

Patients-A random sample of 4237 patients aged 16 and over from two general practices in Staffordshire were mailed a questionnaire enquiring about respiratory symptoms and their severity.

Main results-The severity of respiratory symptoms increased with increasing exposure to cigarette smoke and was greater among manual social classes. Current smokers (odds ratio $(O R)=2.9,95 \%$ confidence limits (CI) 2.3, 3.6), past smokers $(\mathrm{OR}=1.5,95 \% \mathrm{CI} 1.2,1.8)$ and passive smokers $(\mathrm{OR}=1.4,95 \%$ CI $1.0,1.8)$ were more likely to report the more severe respiratory symptoms compared with nonsmokers. Responders from social class $\mathrm{V}$ $(\mathrm{OR}=2.4,95 \%$ CI $1.3,4.4)$ were more likely to report the more severe respiratory symptoms compared with social class I, as were responders from social classes IIIM (OR $=1.3,95 \%$ CI $0.9,1.9)$ and IV $(\mathrm{OR}=1.4,95 \%$ CI $0.9,2.1)$. These effects were independent of each other.

Conclusions-This study has shown that social class is linked to the severity of respiratory symptoms, independently of smoking. Although the need to reduce and quit smoking in manual class households remains a crucial preventive issue, other mechanisms by which social class differences may influence symptom occurrence and severity need to be explored.

(F Epidemiol Community Health 2000;54:340-343)
\end{abstract}

Primary Care Sciences Research Centre, School of Postgraduate Medicine, Keele University, Thornburrow Drive, Hartshill, Stoke on Trent, Staffordshire ST4 7QB

Correspondence to: Mr Trinder

Accepted for publication 22 November 1999
The link between social deprivation and respiratory symptoms is unclear. Higher rates of hospital admission for asthma, ${ }^{1}$ increased asthma mortality $^{2}$ and greater severity of asthmatic symptoms ${ }^{3}$ have been observed in relation to social class and geographical deprivation. By contrast, the prevalence of symptoms such as wheeze has not been consistently found to vary with social class. ${ }^{3-5}$

One explanation of the link observed between asthma mortality and morbidity and social deprivation is the effect of exposure to cigarette smoke.$^{67}$ Smoking is more frequent in deprived groups, ${ }^{8}$ but recent studies indicate that there is uncertainty and controversy as to the exact nature of the association between respiratory symptoms, diagnosed asthma, and smoking, particularly in children. ${ }^{9}{ }^{10}$ We have investigated the role of smoking further in relation to respiratory symptoms in adults, by exploring the relation between such symptoms and smoking and social class in a population based survey in the United Kingdom.

\section{Methods}

A cross sectional survey was carried out in the adult registered populations of two general practices in Staffordshire, one urban, one rural. A random sample of 4237 patients aged 16 and over was selected from the total patients $(n=$ 15 595) registered with the two practices. Patients were mailed a validated questionnaire $^{11}$ enquiring about 10 respiratory symptoms during the previous month. Each symptom was rated for its severity in the previous month according to a five category scale of frequency (never, on one or a few days, on several days, on most days, every day). In the original published paper presenting this scale the authors provided a series of weights for these five categories that, when combined across the 10 questions, produces an overall score of severity ranging from $0-37 .{ }^{11}$ We have adopted this scale as published. A repeat questionnaire was mailed four weeks later to all nonresponders.

The questionnaire asked for the respondent's sex, date of birth and current smoking status, as well as information about both their own and partner's current (or last) occupation. Each respondent's social class was derived using the classification of the Office of National Statistics. ${ }^{12}$ This approach uses the occupation of householders to determine social class for the household as a whole. Households were classified into one of five social classes: I-Professional; II-Managerial; IIIN-Skilled Non-Manual; IIIM-Skilled Manual; IV-SemiSkilled Manual; V-Unskilled Manual.

To explore the effect of smoking, responses to the questionnaire were coded into four categories. These were: current, past, passive, and non-smokers. Current smokers referred to people who had smoked regularly in the past year. Past smokers were those people who had not smoked regularly in the previous year, but had smoked regularly in the past. Passive smokers were defined as those respondents who were neither current or past smokers, but were exposed to cigarette (tobacco) smoke in the household as a result of another person(s) 
Table 1 Prevalence of respiratory symptoms in the past month in 2996 adults from a general population sample

\begin{tabular}{|c|c|c|c|c|c|c|}
\hline \multirow[b]{2}{*}{ Symptom reported in last month } & \multicolumn{2}{|c|}{$\begin{array}{l}\text { Number with } \\
\text { symptoms }\end{array}$} & \multicolumn{2}{|c|}{$\begin{array}{l}\text { Number with } \\
\text { symptoms aged } \\
16-44\end{array}$} & \multicolumn{2}{|c|}{$\begin{array}{l}\text { Number with } \\
\text { symptoms aged } \\
45+\end{array}$} \\
\hline & $n$ & $(\%)$ & $n$ & $(\%)$ & $n$ & $(\%)$ \\
\hline \multicolumn{7}{|l|}{ Day time } \\
\hline Breathlessness during exercise & 1656 & 55.8 & 803 & 57.2 & 853 & 54.5 \\
\hline Breathlessness when not exercising & 692 & 23.2 & 279 & 19.9 & 413 & 26.2 \\
\hline Wheezing & 718 & 24.2 & 322 & 23.0 & 396 & 25.2 \\
\hline Coughing & 1877 & 62.9 & 963 & 68.6 & 914 & 57.9 \\
\hline Chest tightness & 951 & 31.9 & 457 & 32.5 & 494 & 31.3 \\
\hline Fear because of breathing problems & 351 & 11.8 & 138 & 9.8 & 213 & 13.5 \\
\hline \multicolumn{7}{|l|}{ Night time } \\
\hline Wheezing & 619 & 20.8 & 271 & 19.3 & 348 & 22.1 \\
\hline Shortness of breath & 518 & 17.4 & 215 & 15.3 & 303 & 19.2 \\
\hline Coughing & 1419 & 47.6 & 703 & 50.2 & 716 & 45.3 \\
\hline Problems sleeping & 737 & 24.9 & 352 & 25.2 & 385 & 24.6 \\
\hline
\end{tabular}

smoking. Non-smokers had neither smoked in the past year or previous to this period, and were not exposed to cigarette (tobacco) smoke as a result of someone else smoking in the household.

The severity score used was developed for use in asthmatics. ${ }^{11}$ Given that our sample of subjects with respiratory symptoms represented a wider diagnostic group, we have carried out an age stratified analysis. In this, separate analysis was carried out for those aged 16-44 years and those aged 45 years and over, on the basis that chronic obstructive pulmonary disease (COPD) or non-respiratory causes of breathlessness (for example, cardiovascular disease) become more likely in the older age groups, whereas in the younger group this is less likely to be the case.

ANALYSIS

Bivariate analysis using descriptive statistics and statistical tests were used initially to explore the relation between social class, smoking and symptom severity. These relations were then explored further using linear and logistic regression models. In the linear regression, the symptom severity score was regressed against several predictor variables, including age, sex,

Table 2 Median severity score of respiratory symptoms in the past month in 2996 adults from a general population sample

\begin{tabular}{|c|c|c|c|c|c|c|}
\hline & \multirow{2}{*}{\multicolumn{2}{|c|}{ All subjects }} & \multicolumn{4}{|l|}{ Age group } \\
\hline & & & \multicolumn{2}{|l|}{$16-44$} & \multicolumn{2}{|l|}{$45+$} \\
\hline & median & $n$ & median & $n$ & median & $n$ \\
\hline All subjects & 4.1 & $2891^{\star}$ & 4.2 & 1388 & 3.6 & 1503 \\
\hline $\begin{array}{l}\text { Interquartile range } \\
\text { Gender }\end{array}$ & $1.4-8.2$ & & $1.4-8.0$ & & $0.0-8.4$ & \\
\hline Men & 4.2 & 1281 & 4.1 & 610 & 4.2 & 671 \\
\hline Women & $\begin{array}{l}3.6 \\
\mathrm{p}=0.078 \dagger\end{array}$ & 1610 & $\begin{array}{l}4.2 \\
p=0.202\end{array}$ & 778 & $\begin{array}{l}2.8 \\
\mathrm{p}=0.001\end{array}$ & 832 \\
\hline \multicolumn{7}{|l|}{ Smoking status } \\
\hline Current & 5.6 & 661 & 5.6 & 363 & 5.6 & 298 \\
\hline Past & 3.7 & 633 & 2.8 & 176 & 4.2 & 457 \\
\hline Passive & 4.2 & 291 & 4.2 & 190 & 2.8 & 101 \\
\hline Non & $\begin{array}{l}2.8 \\
\mathrm{p}<0.001\end{array}$ & 1246 & $\begin{array}{l}2.8 \\
\mathrm{p}<0.001\end{array}$ & 638 & $\begin{array}{l}2.8 \\
\mathrm{p}<0.001\end{array}$ & 608 \\
\hline \multicolumn{7}{|l|}{ Social class } \\
\hline I & 2.8 & 153 & 2.8 & 79 & 2.8 & 74 \\
\hline II & 2.8 & 962 & 2.8 & 467 & 2.8 & 495 \\
\hline IIIN & 4.2 & 618 & 4.2 & 302 & 2.8 & 316 \\
\hline IIIM & 4.2 & 584 & 5.5 & 254 & 4.2 & 330 \\
\hline IV & 5.0 & 283 & 5.1 & 128 & 5.0 & 155 \\
\hline $\mathrm{V}$ & $\begin{array}{l}6.4 \\
\mathrm{p}<0.001\end{array}$ & 80 & $\begin{array}{l}5.0 \\
\mathrm{p}<0.001\end{array}$ & 27 & $\begin{array}{l}7.0 \\
\mathrm{p}<0.001\end{array}$ & 53 \\
\hline
\end{tabular}

*For 105 patients no morbidity index could be calculated because of missing data. †Test for trend (based on unadjusted linear regression analyses). general practice, smoking status and social class. The logistic regression was carried out to explore the interaction of the effects of smoking and social class on symptom severity and to estimate odds ratios for the size of the associations between the predictor variables and symptom severity. In the logistic regression, the morbidity index was dichotomised into none to moderate and severe symptoms, where none to moderate ranged from scores of $0-4.1$ (up to the median value) and severe referred to all scores above the median value. These were regressed against the same predictor variables as those used in the linear regression. Analysis was carried out in SPSS for Windows version 8.

\section{Results}

SYMPTOM PREVALENCE

After one repeat mailing, there were 2996 replies to the questionnaire (an unadjusted response of 71 per cent). The prevalence of the 10 respiratory symptoms is presented in table 1. The three most prevalent respiratory symptoms reported were day time coughing (63 per cent), breathlessness during exercise (56 per cent) and nocturnal coughing (48 per cent).

SYMPTOM SEVERITY

The overall median severity score for all adult respondents was 4.1 (table 2). Men and women reported a similar severity of symptoms overall. However, older men (45 years and over) had a significantly greater severity score compared with women of the same age. Among smokers, severity was greatest in current smokers, while responders from manual social classes reported a greater severity of symptoms compared with non-manual classes.

SYMPTOM SEVERITY - MULTIVARIATE ANALYSIS We explored these relations in a linear regression model. The morbidity index was regressed against age, sex, general practice, smoking status and social class. After adjusting for all the variables in the model, both smoking status and social class were found to be independently associated with the morbidity index $(p<0.001)$. There was a trend for greater symptom severity among the differing categories of smokers compared with nonsmokers, while responders from the three manual social classes reported a greater severity of symptoms compared with non-manual responders.

To estimate the odds ratios for the independent effects of these variables on symptom severity, an unconditional logistic regression was carried out. Table 3 gives the results. Current smokers (odds ratio $=2.9,95 \%$ CI 2.3, 3.6), past smokers (odds ratio $=1.5,95 \% \mathrm{CI}$ $1.2,1.8$ ) and passive smokers (odds ratio $=1.4$, $95 \%$ CI $1.0,1.8$ ) were more likely to report severe respiratory symptoms compared with non-smokers. Responders from social class V (odds ratio $=2.4,95 \%$ CI $1.3,4.4$ ) were more likely to report severe respiratory symptoms compared with responders from social class I, as were those responders from social classes IIIM (odds ratio $=1.3,95 \%$ CI $0.9,1.9$ ) and IV (odds ratio $=1.4,95 \%$ CI 0.9, 2.1). 
Table 3 Severity of respiratory symptoms by smoking status and social class: measured by odds ratio

\begin{tabular}{lll}
\hline & Odds ratio & $95 \%$ CI \\
\hline Smoking status $\dagger$ & \multicolumn{2}{l}{} \\
Current & 2.9 & $2.3,3.6$ \\
Past & 1.5 & $1.2,1.8$ \\
Passive & 1.4 & $1.0,1.8$ \\
Non (reference) & 1 & - \\
Social class $\dagger$ & \multicolumn{1}{l}{} \\
I (reference) & 1 & - \\
II & 0.9 & $0.6,1.3$ \\
IIIN & 1.1 & $0.8,1.6$ \\
IIIM & 1.3 & $0.9,1.9$ \\
IV & 1.4 & $0.9,2.1$ \\
V & 2.4 & $1.3,4.4$ \\
& $\star$ Adjusted for age, sex, general practice, and either social class or
\end{tabular}
smoking status. $†$ Test for trend $(\mathrm{p}<0.001,1$ degree of freedom).

Table 4 Investigation of the interaction effects between smoking status and social class on symptom severity

\begin{tabular}{lll}
\hline \multirow{2}{*}{ Social class } & \multicolumn{2}{l}{ Smoking status } \\
\cline { 2 - 3 } & Passive/none & Current/past \\
\hline \multirow{2}{*}{ Non-manual } & $392(39.7 \%)^{\star}$ & $390(54.7 \%)^{\star}$ \\
& $\mathrm{RR}=1.0 \dagger$ & $\mathrm{RR}=1.4(1.3$ to 1.5$) \ddagger$ \\
Manual & $191(48.4 \%)^{\star}$ & $351(65.5 \%)^{\star}$ \\
& $\mathrm{RR}=1.2(1.1$ to 1.4$) \ddagger$ & $\mathrm{RR}=1.7(1.5$ to 1.8$) \ddagger$ \\
& & $\mathrm{RR}=1.7(1.3$ to 2.1$) \S$ \\
& & $\mathrm{RR}=1.6(1.3$ to 1.9$)$
\end{tabular}

^Number (percentage) of people with a morbidity score above the median value of 4.1 . Reference category $\ddagger$ Observed relative risk compared with reference category $(95 \%$ confidence intervals). 『Expected crude relative risk on a multiplicative scale. Expected crude relative risk on an additive scale.

There was no evidence of statistically significant positive interaction between the effects of smoking status (current and past compared with passive and non) and social class (nonmanual compared with manual) on symptom severity (table 4). Adjusting for age, sex and general practice, there was no interaction either on a multiplicative scale $(\mathrm{p}=0.580$ in a logistic regression), or on an additive scale ( $\mathrm{p}=0.625$ in a linear regression).

\section{Discussion}

Two potential sources of bias need to be considered. Non-response to the survey may have been differential. In the study, we found response rates were similar for men (72 per cent) and women (70 per cent), while people aged 45 and over were more likely to respond to the questionnaire ( 80 per cent) compared with those aged between 16-44 (63 per cent). This latter difference, however, is unlikely to have affected our main results that concern differences in symptom severity according to smoking status and social class within the group of responders.

A comparison of response rates by social class was not possible as occupational data were only available for those people who returned the questionnaire, and not for the whole sample. However, an ecological measure of social deprivation was available for the whole sample, the census based Townsend ${ }^{13}$ measure. Based on this latter measure, recorded response rates were similar in those living in affluent (75 per cent) and deprived areas (71 per cent).

The second issue is recall bias. When collecting survey data that are dependent on
KEY POINTS

- Respiratory symptom severity was greatest among manual social classes and current smokers.

- Social class was linked to the severity of respiratory symptoms independently of smoking status.

- The need to reduce and quit smoking in manual class households remains a crucial preventive issue.

- Other mechanisms by which social class differences influence symptom occurrence and severity need to be explored.

people recalling information and events that may have occurred several months previously, recall may be influenced by current status. As our main findings concern the association of symptoms with social class and smoking status, misclassification of symptoms would tend to weaken any observed associations. Systematic bias would only occur if smoking status or social class were strongly influencing recall. To tackle this issue in our study, we restricted the period of recall about the occurrence of respiratory symptoms to one month. This does not guarantee complete accuracy of responses, but it allows us to approach the data with a reasonable degree of confidence in the unbiased reporting of symptoms. ${ }^{14}$

A further issue is our choice of respiratory symptom questionnaire. ${ }^{11}$ This was originally developed for use as an outcome measure among diagnosed adult asthmatics, and its characteristics in a broader population have yet to be clearly established. However, we chose this measure because it was symptom-based, it had content and face validity with respect to the symptoms, and was well correlated with measures of general health status.

We found both smoking and social class were linked separately with the severity of respiratory symptoms. The positive relation between cigarette smoking and respiratory symptoms has been reported elsewhere. ${ }^{15}$ Current smokers in our study had a higher prevalence and a greater severity of respiratory symptoms compared with non-smokers.

Prevalence figures for wheeze and asthma have not been consistently found to vary with social class. ${ }^{3-5}$ In our study, the prevalence of respiratory symptoms was higher in respondents from manual social classes compared with non-manual classes. In addition, respondents from manual social classes reported a greater severity of symptoms. This confirms the findings from a previous study of respiratory symptoms. ${ }^{3}$ We found respondents from social class $\mathrm{V}$ were almost two and a half times more likely to report severe symptoms compared with social class I, while people from classes IIIM and IV were approximately one and a half times more likely to report severe symptoms compared with social class I. These differences persisted after adjusting for age, sex, general practice and cigarette smoking. 
Although smoking prevalence was higher in manual groups, we have shown that there was a link between social class and respiratory symptoms that was independent of smoking. The influence of social class on symptom severity cannot be explained by smoking alone.

If the influence of social class on the severity of respiratory symptoms cannot be fully explained by people's smoking habits, what could account for these differences? There are at least two possible explanations. Firstly, social deprivation may be a measure of other factors involved in the aetiology of respiratory symptoms, such as environmental pollution, family history and occupational exposure. Secondly, people in lower social classes may not be receiving equivalent levels of care to those given to their more affluent counterparts, thus increasing the likelihood of persistent symptoms. ${ }^{16}$ People from deprived groups may be less likely to comply with medication, exacerbating their symptoms further, ${ }^{17}$ or they may have restricted access to healthcare. ${ }^{1}$

In conclusion, our study has shown that social class is linked to the severity of respiratory symptoms, independently of smoking. Given the role of smoking in respiratory symptoms and the higher prevalence of smoking exposure in manual class households, the need to reduce and quit smoking remains a crucial preventive issue, particularly in manual class households. However, other mechanisms by which social class differences may influence symptom occurrence and severity need to be explored. We are now examining consultation patterns in patients from different social classes to further disentangle the influence of access to healthcare on these results.
We would like to thank Dr Gordon Thomas, Dr Margaret Jones, and the partners and patients of the Trent Vale Health Centre Stoke on Trent and of the Penkridge Health Centre, Staffordshire for their continued help and support. Thanks also to Dr Michael Lane and Mr Martin Dudgon of the former Staffordshire Family Health Services Authority.

Funding: Staffordshire Family Health Services Authority. Conflicts of interest: none.

1 Halfon N, Newacheck PW. Childhood asthma and poverty: differential impacts and utilisation of health services. Paediatrics 1993;91:56-61.

2 Higgins BG, Britton JR. Geographical and social class effects on asthma mortality in England and Wales. Respir Med 1995;89:341-6.

3 Strachan DP, Anderson HR, Limb ES, et al. A national survey of asthma prevalence, severity, and treatment in Great Britain. Arch Dis Child 1994;70:174-8.

4 Eachus J, Williams $M$, Chan P, et al. Deprivation and cause specific morbidity: evidence from the Somerset and Avon survey of health. BMF 1996;312:287-92.

5 Burr ML, Verrall C, Kaur B. Social deprivation and asthma. Respir Med 1997;91:603-8.

6 Flodin U, Jönsson P, Ziegler J, et al. An epidemiologic study of bronchial asthma and smoking. Epidemiology 1995;6: 503-5.

7 Lundbäck B, Rönmark E, Jönsson E, et al. Longitudinal study results of risk factors for asthma in adults. Eur Respir f 1996; 9 (suppl 23):S24.

8 Department of Health. Health related behaviour: an epidemiological overview. London: HMSO, 1996.

9 Tager IB. Smoking and childhood asthma-where do we stand? Am $\mathcal{F}$ Respir Crit Care Med 1998;158:349-51.

10 Strachan DP, Cook DG. Parental smoking and childhood asthma: longitudinal and case-control studies. Thorax 1998;53:204-12.

11 Steen N, Hutchinson A, McColl E, et al. Development of a symptom based outcome measure for asthma. BMF 1994; 309:1065-8.

12 Office of National Statistics. Standard Occupational Classification. London: HMSO, 1991.

13 Townsend P, Phillimore P, Beattie A. Health and deprivation: inequality and the North. London: Croom Helm, 1988.

14 Horwitz RI, Yu EC. Problems and proposals for interview Horwitz RI, Yu EC. Problems and proposals for interview
data in epidemiological research. Int f Epidemiol 1985;14: data in

15 Senthilselvan A, Chen Y, Dosman JA. Predictors of asthma and wheezing in adults: grain farming, sex, and smoking. Am Rev Respir Dis 1993;148:667-70.

16 Haas JS, Cleary PD, Guadagnoli E, et al. The impact of socioeconomic status on the intensity of ambulatory treatment and health outcomes after hospital discharge for adults with asthma. F Gen Intern Med 1994;9:121-6.

17 Watts RW, McLennan G, Bassham I, et al. Do patients with asthma fill their prescriptions? A primary compliance study. Aust Fam Physician 1997;26 (suppl 1):S4-6. 